\title{
Composing The Good Ship Hibernia and the Hole in the Bottom of the World
}

\author{
S. Roddy \\ Connect Centre, Trinity College \\ Dublin, Dublin 2, Ireland. \\ roddyst@tcd.ie
}

\begin{abstract}
This paper explores topics in embodied cognition, soundscape composition and sonification. It explains the compositional decisions and technical considerations that went into the composition of the piece The Good Ship Hibernia, which is an example of embodied soundscape sonification. This explanation is undertaken within the context of an approach to both sonification design and music composition that accounts for and exploits the embodied aspects of meaning-making in auditory cognition as described in the embodied cognitive science literature.
\end{abstract}

\section{CCS CONCEPTS}

- Applied computing $\rightarrow$ Arts and Humanities, Sound and music computing;

\section{KEYWORDS}

Data-driven, Music, Composition, Sonification, Financial Data.

\section{ACM Reference Format:}

S. Roddy. Composing The Good Ship Hibernia and the Hole in the Bottom of the World. 2017. In Proceedings of $A M$ '17, London, United Kingdom, August 23-26, 2017, 6 pages. https://doi.org/10.1145/3123514.3123520

\section{INTRODUCTION}

This paper discusses some of the technical details and the considerations that went into the composition of a

Permission to make digital or hard copies of all or part of this work for personal or classroom use is granted without fee provided that copies are not made or distributed for profit or commercial advantage and that copies bear this notice and the full citation on the first page. Copyrights for components of this work owned by others than the author(s) must be honored. Abstracting with credit is permitted. To copy otherwise, or republish, to post on servers or to redistribute to lists, requires prior specific permission and/or a fee. Request permissions from Permissions@acm.org.

AM '17, August 23-26, 2017, London, United Kingdom (C) 2017 Copyright is held by the owner/author(s). Publication rights licensed

ACM

to

ACM.

https://doi.org/10.1145/3123514.3123520 soundscape sonification entitled The Good Ship Hibernia and the Hole in the Bottom of the World (The Good Ship Hibernia from here out). This piece mixes the practice of sonification, the representation of data to a listener using sound, with soundscape composition, the composition of aesthetic sound-works from recordings of soundscapes. The piece brings both of these practices together within a wider framework of embodied cognition which is intended to inform compositional choices in a manner which ensures the finished piece faithfully represents the data to the listener. However this is pursued in a manner that is concerned with the exploitation of the aesthetic dimensionality of sound as a medium for encoding, representing and interpreting data.

\section{MEANING-MAKING}

\subsection{Computational Meaning-making}

Meaning-making is the cognitive process by which people create, perceive and assigns meaning in and to their world. There are numerous theories of how this cognitive process operates and of the faculties that are involved. The culturally and scientifically dominant paradigm for meaning making is referred to as the Classical Computational Theory of Mind or computationalism [1]. Computationalism argues that the human mind, as distinct from the brain, operates in the same way as a computer and cognitive tasks, such as decision-making and meaningmaking, are purely computational processes, in which computation is defined by the rule based manipulation of symbols [2]. In this view the meaning of a symbol or perceptual input is computed by its mental manipulation in accordance with a specific set of rules.

\subsection{Embodied Meaning Making}

In recent years a number of researchers have argued that there is more to meaning making in the context of human computer interaction $[3,4,5]$ and auditory display $[6,7,8]$ where it is argued that there is an "embodied" component to meaning-making which can be exploited to design more effective sonifications. 
Embodied cognition is a research strand within cognitive science that studies the relationship between the body and mind with a specific focus on how the physical and perceptual dimensions of the human body shape and define the cognitive dimensions of the human mind. According to Johnson [9] and Varela et al. [10] some aspects of meaning emerge in the coupling between an organism and its environment, as opposed to being entirely mental phenomena, and they are mediated and shaped by bodily interactions with the environment. This approach differs from ecological psychology and ecological psychoacoustics in its focus on the role of the body as the conduit between mind and world.

A number of embodied cognition researchers link embodied cognitive faculties to aesthetic experience in sonic mediums. Brower [11], Cox [12], Johnson and Larson [13], Zbikowski [14], Godøy [15], Johnson [16], Larson [17] and Kendall [18,19] describes how the embodied aspects of cognition are critical to aesthetic dimensionality of sound and music. For these thinkers aesthetics and meaning-making are closely linked with an aesthetic experience being one in which the subjects embodied meaning-making faculties are more fully engaged than normal. It has been argued elsewhere [20] that sonification listening, the act of listening to a sonification in order to obtain information about the original data source, also relies on the embodied component of auditory cognition.

\section{SOUNDSCAPE COMPOSITION}

\subsection{Embodied Soundscape Sonification}

Environmental soundscapes, the environmental variant of the soundscapes defined by Schafer [21], explored in the work of Truax [22] and Westerkamp [23] and extended to sonification by Walker and Kramer [24], provide an interesting class of sounds for use in sonification and datadriven composition. Schafer [21] originally defined the soundscape as any perceptible 'sonic environment', geographical, musical or otherwise which is distinguished from the wider acoustic environment which contains further non-perceptible acoustic components. The Handbook of Acoustic Ecology [25] further defined the soundscape as follows:

An environment of sound (sonic environment) with emphasis on the way it is perceived and understood by the individual, or by a society. It thus depends on the relationship between the individual and any such environment. The term may refer to actual environments, or to abstract constructions such as musical compositions and tape montages, particularly when considered as an artificial environment.
Schafer's definition of the soundscape as the experience of the perceptible signals in an acoustic environment carries the subtle but important distinction that the soundscape results from the filtering and interpretation of the acoustic environment by the perceptual apparatus of the perceiving agent. The second definition presented here carries this further by explicitly highlighting the role of the listeners understanding as crucial to the definition of a soundscape. Truax [22] argues that the relationships between human organisms and their environments are primarily mediated by soundscapes through dynamic processes of embodied cognition. A similar argument about the relationship between environment and organism is put forward by Maturana and Varela [26] and Varela et al. [10]. They argue that the organism and environment share a close relationship of mutual specification or structural coupling. This is a closed loop relationship in which the environment defines and shapes the organism's perceptual and cognitive functions by acting on and shaping the organisms physical body. In turn those cognitive functions define the organism's experience of, and behaviours in, the environment at the levels of perception, cognition and interaction. This differs from Gibson's ecological view of perception in its focus on the physical body as the conduit between mind and world. The environments ability to shape the cognitive faculties of the organism is constrained by and mediated in terms of the physical body and the organism's ability to shape the environment is constrained by and mediated in terms of the physical body. Sound localisation by interaural time and interaural level difference provides a relevant example of how the physical body's constraint and mediation of the environment defines the organism's cognitive faculties in terms of the listener's ability to determine the location of a sounds source.

Soundscapes are embodied to the degree that they result from the constraints imposed upon, and the mediation of, the acoustic environment by the listener's physical body. This suggests that the embodied cognitive capacities discussed previously might be at play in the listener's perceptual organisation and conceptual understanding of the soundscape. Kendall [18][19] has argued that the embodied cognitive faculties of image schemata and conceptual blending are crucial to the emergence of meaning in soundscape listening in the context of electroacoustic music. Droumeva et. al. [27] have demonstrated how the experience of a soundscape and its conceptual interpretation can be structured on the basis of conceptual metaphors and image schemata in an auditory display context. For a sound to be embodied it need not represent some aspect of the human body and it need not sound as though it originated with the human body either. This paper argues that auditory cognition itself is embodied and as a result all sounds are understood and made meaningful in terms of a mind that has been defined and 
shaped by the physical human body. The embodied approach advocated here involves using and controlling sounds in ways that exploit those aspects of cognition, which have been shaped by the body; it is the nature of cognition, and not the sounds themselves, that is considered embodied.

The term soundscape sonification is used in this paper to refer to the use of recordings of real-world locations, the use of soundscapes which have been composed from recording of real world environmental elements, and to the use of soundscapes which have been composed from synthesised elements in the sonification of data. A number of composers and sonification researchers and practitioners have explored and applied similar concepts of soundscape sonification.[24,28,29,30,31,32,33,34,35,36,37,38]

Walker and Kramer [24] recognise the importance of environmental sound to sonification. They argue that traditional psychoacoustics does not offer a comprehensive description of how listeners hear and think about real world sound and suggest that an ecological psychoacoustics that considers the relationship between organism and environment is required for the design of effective sonifications. An embodied soundscape sonification can be thought of as a sonification in which environmental soundscape elements are organised, mapped to data and presented in a manner that exploits the embodied nature of auditory cognition.

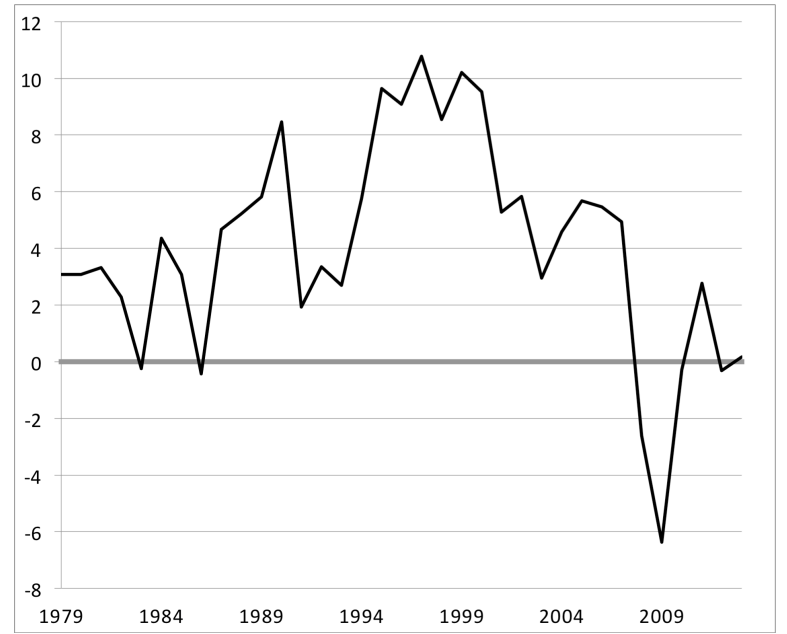

Figure 1. World Bank's figures for Irish GDP growth rate from 1979 to 2013

\subsection{Aesthetics in Embodied Soundscape Sonification}

Historically, music and computer music have been critical contributing fields to sonification research and practice. An increasing number of researchers in the area place the role of aesthetics as a primary concern and call for a more focused investigation of the aesthetic dimensions of sonification [39,40,41,42]. Aesthetics and cognitive meaning-making are closely intertwined and it is the listeners' cognitive meaning-making faculties that drive both aesthetic and mundane experience alike [8]. In this point of view, aesthetic experiences are those which effectively exploit a person's embodied cognitive faculties to create particularly meaningful experiences. A similar line of thought is developed by Fauconnier and Turner [43] and is extended to music and auditory cognition by thinkers like Zbikowski, Brower, Larsson, Cox and Kendall cited earlier. As such, a fully realised and serious account of the role of the human body in sonification listening, a practice chiefly concerned with making data meaningful, would necessarily account for aesthetic experience. This might suggest that when a sonification is effectively communicating data to a listener, it is creating a more heightened aesthetic experience for that listener, as discussed. This sentiment is echoed by Vickers and Hogg [41] who argue that it is not necessarily useful or meaningful to distinguish between musical and nonmusical sonifications.

\section{COMPOSING THE GOOD SHIP HIBERNIA}

The Good Ship Hibernia is an Embodied Soundscape Sonification which explores the impact of Ireland's recent financial crash. The piece uses the World Bank's figures for the growth rate of Ireland's gross domestic product (GDP) from 1979 to 2013 (represented in figure 1). GDP data is a commonly used indicator for measuring the economic performance of a region or country. It is a measurement of the market value of all goods and services produced in a region within a specific time frame. GDP growth rate is a measurement of the rate at which GDP increases and decreases over time. The composition of The Good Ship Hibernia began with a consideration of how an abstract measurement like GDP might be contextualised for and presented to a listener so that they might experience it in a more visceral and tangible manner. The piece uses both soundscape and harmonic materials and employs sonification techniques to reflect this data. The piece is structured around an image schema and a conceptual metaphor. It was decided to draw upon the theory of image schemata to represent the data in a manner faithful to the original data source and the theory of conceptual metaphor to frame the data in a manner faithful to the original data source. The question of how the data is framed is crucial because sounds necessarily have personal, social, political and cultural dimensions [49] and these dimensions need to be accounted for in design of the sonification.

Image schemas, first discussed by Johnson [44] and Lakoff [45], are commonly shared fundamental gestalt patterns of embodied experience that provide people with a common basis for organising their experience, meaning- 
making and reasoning. Johnson and Rohrer [46] further describe embodied schemata as "recurrent patterns of bodily experience, which preserve the topological structure of the perceptual whole". Embodied schemata impose an elaborate and detailed structure on the chaos of raw experience independent of and prior to the processes of conceptualisation and language. Each schema has its own internal logical syntax, which provides a basis for reasoning and inference. Conceptual metaphors are a specific type of cross-domain mapping where embodied schemata from familiar areas of experience, termed source domains, are mapped onto unfamiliar target domains that would otherwise be meaningless or unknowable, in order to make them meaningful (for further details see [47]). A classic example of a conceptual metaphor is the LIFE IS A JOURNEY metaphor in which the source-path-goal schema

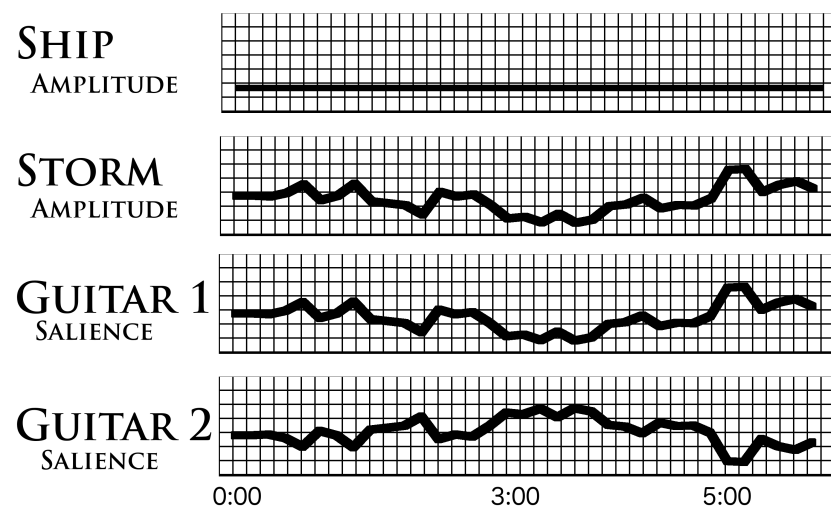

Figure 2. Data to sound mapping strategy

underlying a subject's experiences of journeying is mapped to lend familiar structure to the abstract concept of love. This allows life to be conceptualised as a journey with a beginning, middle and end where people are travelers on a common path along which they may encounter difficulties and perils. In a conceptual metaphor, all source domains are ultimately grounded in the embodied schemata of sensorimotor experience[47,48].

The Good Ship Hibernia uses the conceptual metaphor of a maritime journey where "smooth sailing" and "good weather" represent "good times" and "rough seas" and "bad weather" represent "bad times". While the growth rate is strong the sailing is smooth and weather is good. When the growth rate shrinks the weather becomes stormy and seas become rough. This specific conceptual metaphor was first discovered and studied by Zołnowska [50]. It was selected in order to frame the data in terms of a balance between "good times" and "bad times". The sense of balance between a smooth and stormy soundscape shifts in accordance with the data. Harmonic material also sounds throughout the journey. This material was performed in response to the soundscape of the sea journey with the perceived salience and timbral character of the performance determined by the GDP data. The image schema chosen was the balance schema, first discussed by Johnson [44]. This was chosen to represent level of balance in GDP figures.

The GDP data is represented in the piece in the balance between the sounds of good weather with smooth sailing on one hand and bad weather with rough seas on the other. The soundscape elements were retrieved from a number of sources including, https://www.freesound.org/ and the BBC Sound Effects Library. Original sounds were also recorded for the piece. Two individual soundscape elements were used in the sonification. The base piece was intended to evoke the soundscape one would expect while experiencing smooth sailing on an old wooden ship. This is labeled

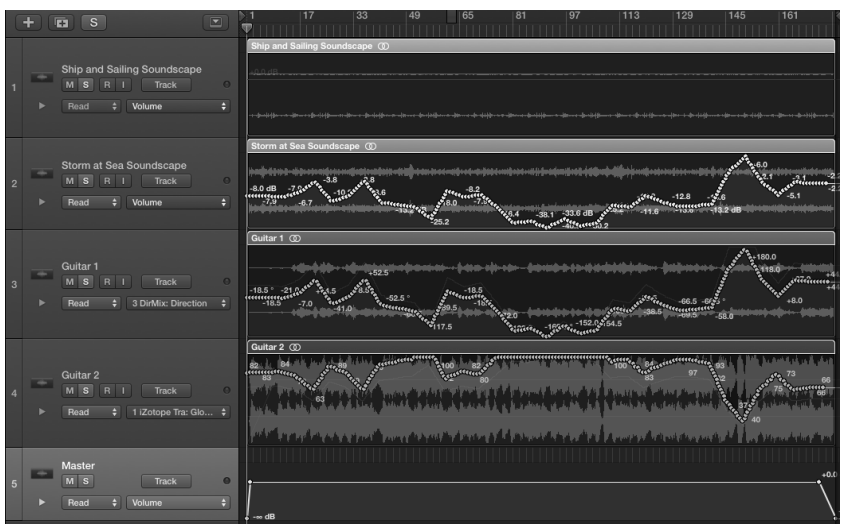

Figure 3. Logic Pro X Project File

"Ship" in figure 2. It is composed from a number of recordings of creaking wood and rope, boats gently breaking through the waves, and the calls of seabirds. The second element is composed from recordings of rough and stormy weather to evoke the soundscape of a storm at sea and was designed to fit into or augment the ship soundscape. This is labeled "Storm" in figure 2. This soundscape was created using Logic Pro $\mathrm{X}$ to arrange and compose the soundscape elements and Csound to format and map the data, to midi. This midi information was in turn ported back to Logic Pro X to control the amplitude of the Storm soundscape. This is represented in figure 3 above. The amplitude of the ship soundscape holds steady throughout the piece. The amplitude of the soundscapes is modulated in order to control the perceived salience or perceptibility of the storm on the basis of the data. Once these soundscape elements had been mapped to the data the harmonic material was generated. This material was performed on electric guitar in response to the soundscape of the sea journey. There are two distinct forms of harmonic material present a foreground melodic component and a background chordal accompaniment. The individual 
notes and chords are not directly determined by the data but are rather an interpretative response to the soundscape. The GDP data was mapped to control the perceived salience of this material by modulating a battery of auditory parameters consisting of amplitude gain, panning, overdrive, distortion, bitcrushing, reverb, and eq (Izotope Trash 2, Izotope Ozone Reverb, Native Instruments Guitar Rig 5 and EQ). This control of perceived salience on the basis of the GDP data is represented in figure 2. The point of this harmonic material was to provide a background context or counterbalance against which the changes in GDP might be rendered more obvious to the listener. This is exemplified when the stormy elements of the soundscape reach a level of ferocity which overcomes that of the improvised harmonic material. The piece was recently performed in concert at the 2017 International Conference on Auditory Display. Informal feedback reflected positively on the compelling nature of the metaphor, the vivid character of the soundscape and the overall communicative nature of the piece. It will also be presented in installation format during the 2017 Audio Mostly conference.

\section{ACKNOWLEDGMENTS}

This publication has emanated from research supported in part by a research grant from Science Foundation Ireland (SFI) and is co-funded under the European Regional Development Fund under Grant Number 13/RC/2077.

\section{REFERENCES}

[1] H. Putnam. 1967. Psychological predicates. Art, mind, and religion. University of Pittsburgh Press, Pittsburgh, 37-48.

[2] H. Gardner. 1985. The Mind's New Science. Basic Books, New York

[3] P. Dourish. 2004. Where the action is: the foundations of embodied interaction. MIT press, Massachusetts.

[4] J. Hurtienne and J.H. Israel. 2007. Image schemas and their metaphorical extensions - Intuitive patterns for tangible interaction. In Proceedings of the 1st International Conference on Tangible and Embedded Interaction 2007. ACM Press, 127-134.

[5] M. Imaz and D. Benyon. 2007. Designing with blends: conceptual foundations of human-computer interaction and software engineering methods. MIT Press, Massachusetts.

[6] D. Worrall. 2013. Understanding the need for microgestural inflections in parameter mapping sonification. In Proceedings of the 19th International Conference on Auditory Display. Lodz, Poland.

[7] A.N. Antle, G. Corness and A. Bevans. 2011. Springboard: designing embodied schema based embodied interaction for an abstract domain. Springer Human-Computer Interaction Series: Whole Body Interaction (2011), 7-18.

[8] M. Leman. 2008. Embodied music cognition and mediation technology. MIT Press, Massachusetts.

[9] M. Johnson. 2013. II. Identity, Bodily Meaning, and Art. Consciousness, Literature \& the Arts, 32, 15.

[10] F.J. Varela, E.T. Thompson and E. Rosch. 1991. The Embodied Mind: Cognitive Science and Human Experience. MIT Press, Massachusetts.

[11] C. Brower. 2000. A cognitive theory of musical meaning. Journal of Music Theory, 44(2), 323-379.

[12] A. Cox. 2001. The mimetic hypothesis and embodied musical meaning. Musicae Scientiae, 5(2), 195-212.

[13] M. Johnson and S. Larson. 2003. "Something in the way she moves" -Metaphors of musical motion. Metaphor and Symbol, 18(2), 63-84.

[14] L.M. Zbikowski. 2005. Conceptualizing music: Cognitive Structure, Theory, and Analysis. Oxford University Press, New York.

[15] R.I. Godøy. 2006. Gestural-sonorous objects: embodied extensions of Schaeffer's conceptual apparatus. Organised Sound, 11(02), 149-157.

[16] M. Johnson. 2008. The meaning of the body: aesthetics of human understanding. University of Chicago Press, Chicago.

[17] S. Larson. 2010. Musical forces: motion, metaphor, and meaning in music. Bloomington: Indiana University Press, Indiana.

[18] G. S. Kendall. 2010. Meaning in electroacoustic music and the everyday mind. Organised Sound, 15(01), 63-74.

[19] G. S. Kendall. 2014. The Feeling Blend: Feeling and emotion in electroacoustic art. Organised Sound, 19(02), 192-202.

[20] S. Roddy. 2015. Embodied Sonification. PhD Dissertation, Trinity College, Dublin, Ireland. URL: http://hdl.handle.net/2262/80558

[21] P. Schaeffer. 1966. In search of a concrete music. Trans. John Dack, Christine North. University of California Press, Los Angeles.

[22] B. Truax. 1984. Acoustic Communication. Ablex Publishing Corporation, Norwood, NJ.

[23] H. Westerkamp. 1999. Soundscape composition: Linking inner and outer worlds. Soundscape Newsletter, Amsterdam, Holland.

[24] B.N. Walker and G. Kramer. 2004. Ecological psychoacoustics and auditory displays: Hearing, grouping, and meaning making. Ecological Psychoacoustics, 150-175.

[25] B. Truax. 1978. Handbook for Acoustic Ecology, Originally published by the World Soundscape Project, Simon Fraser University.

[26] H. R Maturana. and F.J. Varela. 1987. The tree of knowledge: The biological roots of human understanding. New Science Library/Shambhala Publications.

[27] M. Droumeva, A.N. Antle, G. Corness and A. Bevans. 2009. Springboard: Exploring embodied metaphor in the design of sound feedback for physical responsive environments. In Proceedings of the 15th International Conference on Auditory Display, Copenhagen, Denmark. 
[28] W. W. Gaver. 1993. Synthesizing auditory icons. In Proceedings of the INTERACT'93 and CHI'93 Conference on Human Factors in Computing Systems. ACM Press 228-235.

[29] M. Fernström and E. Brazil. 2001. Sonic Browsing: an auditory tool for multimedia asset management. Hiipakka, J, Zacharov, N., \& Takala, T., (Eds). In Proceedings of the 7th International Conference on Auditory Display (ICAD2001). Espoo, Finland.

[30] E. Brazil and M. Fernström. 2007. Investigating ambient auditory information systems. In Proceedings of the 13th International Conference on Auditory Display, Montreal, Canada, 326-333.

[31] T. Hermann and H. Ritter. 2004. Sound and meaning in auditory data display. In Proceedings of the IEEE, 730-741.

[32] T. Hermann, T. Hildebrandt, P. Langeslag and S. RinderleMa. 2015. Optimizing aesthetics and precision in sonification for peripheral process-monitoring. In Proceedings of the 21st International Conference on Auditory Display (ICAD 2015). Graz, Austria.

[33] B.S. Mauney and B.N. Walker. 2004. Creating functional and livable soundscapes for peripheral monitoring of dynamic data. In Proceedings of the 10th International Conference on Auditory Display (ICAD-04), Sydney, Australia.

[34] M.A. Nees and B.N. Walker. 2009. Auditory interfaces and sonification. The Universal Access Handbook, 507-521.

[35] F. Kilander and P. Lonnqvist. 2002. A whisper in the woods - an ambient soundscape for peripheral awareness of remote processes. In Proceedings of the 8th International Conference on Auditory Display (ICAD 2002), Kyoto, Japan.

[36] K.E. Wolf, G. Gliner and R. Fiebrink. 2015. A model for data-driven sonification using soundscapes. In Proceedings of the 20th International Conference on Intelligent User Interfaces Companion. ACM, 97-100.

[37] A. Polli. 2012. Soundscape, sonification, and sound activism. AI \& Society, 2(2012), 257- 268.

[38] N. Barrett and K. Mair. 2014. Sonification for geoscience: listening to faults from the inside. In EGU General Assembly Conference Abstracts, 4489.

[39] F. Grond and T. Hermann. 2012. Aesthetic strategies in sonification. AI \& Society, 2(2012), 213-222.

[40] S. Barrass and P. Vickers. 2011. Sonification design and aesthetics. In The Sonification Handbook Hermann, T., Hunt, A., \& Neuhoff, J. G., (Eds.). Logos Publishing House, Berlin, Germany, 145-171.

[41] P. Vickers and B. Hogg. 2006. Sonification abstraite/sonification concrete: An 'aesthetic perspective space' for classifying auditory displays in the ars musica domain, in Proceedings of the 12th International Conference on Auditory Display, London, UK.

[42] S. Roddy and D. Furlong. 2014. Embodied Aesthetics in Auditory Display. Organised Sound, 1(2014), 70-77.

[43] G. Fauconnier and M. Turner. 2002. The way we think: conceptual blending and the mind's hidden complexities. Basic Books, New York.
[44] M. Johnson. 1987. The body in the mind: the bodily basis of meaning, imagination, and reason. University of Chicago Press, Chicago.

[45] G. Lakoff. 1987. Fire, and dangerous things. What categories reveal about the mind. University of Chicago Press, Chicago.

[46] M. Johnson and T. Rohrer. 2007. We are live creatures: Embodiment, American Pragmatism, and the cognitive organism. In Body, language and mind, Vol. 1: Embodiment T. Ziemke, J. Zlatev, \& Frank R.(Eds.) Mouton de Gruyter, Amstedam, 17-54.

[47] G. Lakoff and M. Johnson. 1980. Metaphors we live by. University of Chicago Press, Chicago.

[48] G. Lakoff and M. Johnson. 1999. Philosophy in the flesh: The embodied mind and its challenge to western thought. Basic books, New York.

[49] S. Voegelin. 2010. Listening to noise and silence: Towards a philosophy of sound art. Bloomsbury Publishing, USA.

[50] I. Żołnowska. 2011. Weather as the source domain for metaphorical expressions. AVANT, Pismo Awangardy Filozoficzno-Naukowej, 1(2011), 165-179. 